$\underline{\text { Review Article }}$

\title{
EXPLORATION OF MICROORGANISMS AS A POTENTIAL SOURCE OF XANTHINE OXIDASE INHIBITORS: AN UPDATED REVIEW
}

\author{
UMA RAJESWARI BATCHU ${ }^{a^{*},}$ JOSHNA RANI SURAPANENIa
}

aDepartment of Pharmaceutics, Institute of Pharmaceutical Technology, Sri Padmavathi Mahila Viswavidyalayam, Tirupati, 517502, India Email: umarajeswaribatchu@gmail.com

Received: 22 Sep 2018 Revised and Accepted: 13 Nov 2018

\begin{abstract}
Nowadays the prevalence of hyperuricemia has significantly increased in which serum uric acid levels are exceeding the normal range. Gout is the predominant clinical implication of the hyperuricemia, but many clinical investigations have confirmed that hyperuricemia is an independent risk factor for cardiovascular disease (CVD), hypertension, diabetes, and many other diseases. The xanthine oxidase (XO) converts hypoxanthine to xanthine and ultimately to uric acid, and the irreversibly accumulated uric acid causes hyperuricemia associated with gout. Hence specific and selective xanthine oxidase inhibitors (XOI) are potentially powerful tools for inactivating target XO in the pathogenic process of hyperuricemia (Gout). The objective of the current study was to overview the various XOI isolated from the microorganisms. Microorganisms have been employed for several decades for the large-scale production of a variety of bio-chemicals ranging from alcohol to antibiotics and as well as enzyme inhibitors. Currently available XOI (allopurinol and febuxostat) for the treatment of gout have been exhibiting serious side effects. Thus, there is a need to search for new molecules to treat hyperuricemia and its associated disorders. At present, microbes have been unexplored in the development of successful products for the management of XO-related diseases. Hence, the present review focused on novel XOI produced from various microbial species such as Actinobacteria, lichens, bacteria, endophytic fungi and mushrooms, which can be expected to play an important role in the ongoing transition from the empirical screening to the real rational drug design.
\end{abstract}

Keywords: Xanthine oxidase inhibitors, Hyperuricemia, Actinobacteria, Bacteria, Fungi, Lichens

(C) 2018 The Authors. Published by Innovare Academic Sciences Pvt Ltd. This is an open-access article under the CC BY license (http://creativecommons.org/licenses/by/4.0/) DOI: http://dx.doi.org/10.22159/ijpps.2018v10i12.29897

\section{INTRODUCTION}

Hyperuricemia has long been established as the major etiological factor in various disorders such as gout, urolithiasis, chronic kidney disease (CKD), tumor lysis syndrome (TLS) and various cardiovascular diseases (CVD) $[1,2]$. Hyperuricemia results due to high serum urate levels, which is attributed to its overproduction or underexcretion. Gout remains the most common among all pathologies associated with hyperuricemia. In India, approximately $0.12-0.19 \%$ population being affected by gout, and its prevalence has been more in men aged above $50 \mathrm{y}$ than premenopausal women as estrogen hormone helps in urate clearance [3,4]. Gout was described by Hippocrates as "The disease of kings" owing to its association with a rich diet [5]. The xanthine oxidoreductase (XOR) is generally recognized as the key factor in hyperuricemia, recognized as the terminal enzyme of purine catabolism in humans. Mammalian XO (XO; EC 1.1.3.22) and xanthine dehydrogenase (XDH) (XDH; EC 1.1.1.204) are interconvertible forms of the same gene product known as XOR catalyzing the hydroxylation of hypoxanthine to xanthine and xanthine to uric acid [6-8]. This process is a source of reactive oxygen species (ROS) as a byproduct of uric acid, which being associated with diverse pathological events including inflammation, metabolic disorders, cellular aging, atherosclerosis, Parkinson's disease, Alzheimer's dementia, reperfusion injury of brain or heart and carcinogenesis [9-11]. The detailed structure, physiological and pathological role of XOR was reviewed previously [12]. The strategy involves the inhibition of the XO appears to be safer as it inhibits circulating levels of uric acid as well as vascular oxidative stress and associated disorders. Till date, only allopurinol, a purine analog, Febuxostat and Topiroxostat, nonpurine based selective inhibitors have been clinically approved as XO inhibitors [13]. Unfortunately, allopurinol is being associated with an infrequent but severe hypersensitivity [14]. Clinically nonpurine analogs (Febuxostat and Topiroxostat) provides greater hyperuricemic activity and less toxicity than allopurinol. However, hypersensitivity reactions of febuxostat also reported [15]. Nevertheless, topiroxostat exhibits high bioavailability and safety in humans, but side effects are not well explored owing to the short duration of clinical use in Japan [16]. In view of the drawbacks of existing therapies, there is a need to develop novel selective inhibitors of XO. Plants have served as an excellent source of novel medicinal compounds [17]. However, the inherent bottleneck encountered by the pharmaceutical industry in their bulk production as it requires huge quantities of biomass for their extraction which eventually threatens the existence of these plants. Moreover, enzyme inhibitors isolated from microbial sources are potent low molecular weight compounds derived from the hydrolysis of macromolecular substances when compared to inhibitors derived from plants and animals [18].

Several review articles focusing on the XOI of diverse sources such as plants, synthetic analogs have been published, serving as a starting point for exploration [19-23]. Thus the alternative resources were embattled to substitute these Phyto medicinals. It has been amply demonstrated by various studies that the metabolites produced by microorganisms, in particular, are recognized as a resource for numerous therapeutic moieties [24]. Therefore the objective of our present review is to summarize the various XOI derived from microbial origin. This is the first review exploring the updates of various XOI from microorganisms.

\section{XOI from various microbial sources}

Since several decades XOI has been screened and synthesized from various sources (fig. 1). Selected microorganisms, including bacteria, fungi, and yeasts have been globally studied for the bio-synthesis of economically valuable preparations of various enzymes and enzyme inhibitors for commercial applications $[25,26]$. In view of their medicinal potential, they have been screened for the isolation of XOI.

\section{Bacteria}

Two specific XOI has been isolated from the culture filtrate of Alcaligenes aquamarinus No.655, and Bacillus cereus No. A-73 strains [27]. One among is identified as 2,8-dihydroxy adenine which was synthesized newly by microbial route (Alcaligenes aquamarinus No.655), but previously by chemical route [28]. The inhibitor has 
shown $50 \%$ inhibition at a concentration of $3 \times 10-6 \mathrm{M}(0.5 \mathrm{~g} / \mathrm{ml})$ on rat liver $\mathrm{XO}$ and $2 \times 10-6 \mathrm{M}(0.33 \mathrm{~g} / \mathrm{ml})$ on milk XO, respectively. As well as another strain identified as Bacillus cereus produced 5formyluracil, a potent XOI, reported previously by microbial route [18].

A potent XOI, alkalone was identified and purified from the fermentation broth of a marine bacteria, Agrobacterium aurantiacum N-81 106[29]. When cultivation conditions of $A$. aurantiacum N-81 106 were changed using a 1000 liter fermenter, alkalone was not produced, and another strong XOI, Hydroxy alkalone, was found to be produced instead of akalone and $\mathrm{IC}_{50}$ value was $4.6 \mu \mathrm{m}$ against XO [30].

A new method was explored to isolate the novel XOI from the fermentation broth of Lactobacillus rhamnosus [31] and furthermore 51 novel Acetobacter and Gluconobacter strains were screened to isolate XOI. Nevertheless, only seven strains have produced the inhibitors showing the more than $30 \%$ inhibition. In particular Acetobacter pasteurianus strain, AHUO1 has shown 73.6\% inhibition [32, 33].

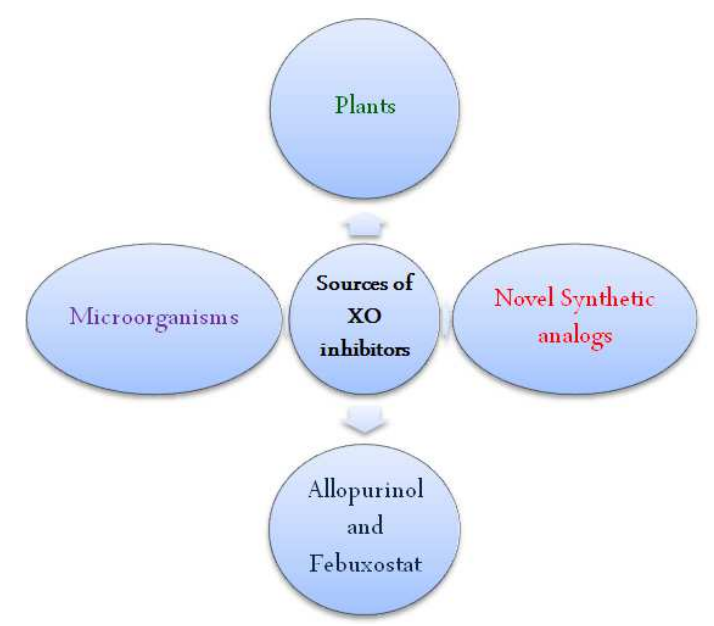

Fig. 1: Various sources of XO inhibitors (Self-designed)

\section{Actinobacteria}

Actinobacteria especially Streptomyces is a proven source of microbial enzyme inhibitors. A new compound, 5-formyl uracil has been isolated from the culture broth of Streptomyces species and has shown strong inhibition against XO [18]. This is the only report on actinobacteria as a source of XOI.

\section{Lichens}

Lichens are fungal species which are obligate symbionts in plants. Lichens have long been recognized to contain bioactive compounds. Many natural lichens and cultured lichens have been screened for their biological activities, and several novel compounds were also isolated and identified. The phenolics and oxidative derivatives found in the lichens might be responsible for the inhibition of xanthine oxidase $[34,35]$. The natural thallus of Bulbothrix setschwanensis was screened for bioactive compounds and found to be composed of mycobiont and photobiont-producing atranorin (a depside) and salazinic acid (a depsidone)[36]. It was reported that the acetone extract of the natural thallus and cultured tissue of $B$. setschwanensis was found to have inhibitory activity on the XO. The $\mathrm{IC}_{50}$ value was identified as 44.7 and $52.1 \mu \mathrm{g} / \mathrm{ml}$ for cultured tissue and natural thallus respectively [37]. Furthermore, recently 31 species of lichens belong to Graphidaceae were reported for their ability to inhibit XO. Among that Graphina glaucorufa, G. multistricta, G. salacinilabiata, G. assamensis, G. nakanishiana, and Phaeographosis indica has shown strong inhibition of $\mathrm{XO}$ with the lower IC 50 value of $3-4.8 \mu \mathrm{g} / \mathrm{ml}$ when compared to standard allopurinol having an $\mathrm{IC}_{50}$ value of $6.37 \mu \mathrm{g} / \mathrm{ml}$ [38].

\section{Endophytic fungi}

Over the last two decades, endophytic fungi have been demonstrated to be a rich and reliable source of novel bioactive compounds possessing antimicrobial, anticancer, neuroprotective, insulin-mimetic, anti-oxidant properties that may foster great medicinal or agricultural potentials [39, 40]. Endophytic fungi colonize the plants internally without apparent symptoms of their ubiquitous existence and are increasingly being prospected as underexplored resources of novel bioactive compounds [41]. Exploring endophytic fungi for XO inhibition is a nascent area with very scanty preliminary data [42]. Together medicinal plants, endophytic fungi offer themselves as a relatively reliable source of natural products which could inhibit XO and probably enters the medical field as an antihyperuricemic drug. Fusaruside is a chemically a new cerebroside, characterized from the chloroformmethanol (1:1) extract of Fusarium sp. IFB-121, an endophytic fungus in Quercus variabilis with an $\mathrm{IC}_{50}$ value of $43.8 \pm 3.6 \mu \mathrm{m}$. In addition to Fusaruside, a known cerebroside isolated from Fusarium sp. has shown XO inhibitory activity with an $\mathrm{IC}_{50}$ value of $55.5 \pm 1.8$ $\mu \mathrm{m}$ [43]. As well as phenolic compounds isolated from endophytic chaetornium sp residing in Nerium oleander $L$ (Apocyanaceae) has exhibited an XO inhibitory activity and the $\mathrm{IC}_{50}$ value was found to be $109.8 \mu \mathrm{g} / \mathrm{ml}[44]$.

Recently XOI has been isolated from novel species of Muscodor, sterile endophytic fungi. Culture filtrates of 7 species of Muscodor isolated from Cinnamomum and Aegle marmelos. Amongst, the chloroform extract of $M$. darjeelingensis exhibited the maximum XOI with an $\mathrm{IC}_{50}$ of $0.54 \mathrm{~g} / \mathrm{ml}$ which was much lower to allopurinol but higher when compared to febuxostat. Nevertheless, $88 \%$ reduction in uric acid production by the extract of $M$. darjeelingensis was similar to allopurinol [45]. Similarly, 19 fungal endophytes were isolated from the medicinal plant Tinospora cordifolia and evaluated for their XO inhibitory activity. In the qualitative assay, Out of 19 fungal endophytes, 7 endophytes exhibited $>30 \%$ XO inhibition, of which isolates \#1 TCSTITPLM, \#53 TCSTITPLM, \#105 TCSTITPLM, and \#83 TCSTITPLM were found to exhibit XO inhibition in the range of $38-45 \%$. Ethyl acetate and chloroform extract of \#1 TCSTITPLM and \#53 TCSTITPLM demonstrated potent XO inhibitory action of 69 and $63 \%$ respectively [46]. new culture filtrates of 42 endophytic fungi were screened for XO inhibition in the process of searching for new XOI. The chloroform extract of culture filtrate \#1048 AMSTITYEL has exhibited the potential inhibition of XO with an $\mathrm{IC}_{50}$ value of $0.61 \mu \mathrm{g} / \mathrm{ml}$ which was better than allopurinol $\left(\mathrm{IC}_{50}\right.$ of $0.937 \mu \mathrm{g} / \mathrm{ml}$ ) but lower than febuxostat (IC 50 of $0.076 \mu \mathrm{g} / \mathrm{ml}$ ). The endophyte was identified as Lasiodiplodia pseudotheobromae isolated from Aegle marmelos [47].

Furthermore, endophytic fungi, Aspergillus niger IFB-E003 isolated from Cyndon dactylon has screened for XOI. The fraction of the Aspergillus niger extract has shown four known compounds naphtha $\gamma$ pyrones such as rubrofusarin B, fonsecinone A, a sperpyrone $\mathrm{B}$, and auraspernone A. Amongst, auraspernone $\mathrm{A}$ has shown XO inhibition with an $\mathrm{IC}_{50}$ value of $10.9 \mu \mathrm{mol}$. Moreover, rubrofusarin $\mathrm{B}$ and auraspernone A were also proved as strong coinhibitors on XO [42].

\section{Mushrooms}

Over the decade's mushrooms have been used not only as a source of food, but also remarkable and unexplored source of new biologically active natural products [48]. Mushrooms belong to Basidiomycota of fungi, has received great interest because it contains a large number of biologically active compounds such as polysaccharides, glycoproteins, triterpenes, and antibiotics [49]. Recently mushrooms are being explored as a potential source of XO inhibitors. Flavonoids and polyphenolic crude extracts have been reported to exhibit XO inhibition $[50,51]$ besides the different flavonoid containing plant species, mushrooms also represents a potential source of such compounds $[52,53]$. An unusual compound, 5-methyl-3 (2H)-furanone derivative (inotilione) was isolated from the fruiting body of the mushroom Inonotus sp. which has exhibited XO inhibition. The fruiting bodies were subjected to ethanol and chloroform-methanol extraction and purification to isolate the compounds exhibiting XO inhibition [54]. 
The acetonic, methanolic and hot water extracts from the fruiting bodies of Pleurotus salmoneoshamineus and $P$. nebrodensis were reported to have XO inhibition which was found to be increased with increasing concentrations $[55,56]$. In a similar way, a new compound was purified from the aqueous extract of Pleurotus ostreaus and has exhibited $\mathrm{XO}$ inhibitory activity with an $\mathrm{IC}_{50}$ value of $0.9 \mathrm{mg} / \mathrm{ml}$ [57].

A new species of central European Phellinoid Hymenochaetaceae (Phellinus sesulato) have screened for XOI. The in vitro antioxidant and XO inhibitory assays demonstrated that most of the selected species possess remarkable antioxidant and XO inhibitory action [58].

A new study was reported in which fermented mushroom water extracts with lactic acid bacteria were exhibited XO inhibition. Fermented mushroom water extracts have increased the free radical scavenging activity, and the antioxidant activity of fermented mushroom extracts was further confirmed by XO inhibition [59]. As well as the above species XO inhibitory activity of aqueous and organic (n-hexane, chloroform, and 50\% methanol) extracts of 47 wild-growing mushrooms native to Hungary have been reported. Among the 47 species, Hypholoma fasciculare (IC50=67.76 \pm 11.05 $\mu \mathrm{g} / \mathrm{ml}$ ), Suillus grevillei (IC50 $=13.28 \pm 1.58 \mu \mathrm{g} / \mathrm{ml}$ ), and Tricholoma populinum (IC50=85.08 $\pm 15.02 \mu \mathrm{g} / \mathrm{ml}$ ) were exhibited high inhibitory activity [60]

\section{CONCLUSION}

The disease burden of hyperuricemia remains a major problem and may be increasing day by day. As described in this article, the rich diversity of microorganisms with their unique characteristics emerged as a potential source for the discovery of XOI. This review is a fine effort to compile and present XOI from microbial sources to encourage further research to use natural microbial XOI in the management and treatment of hyperuricemia and other associated disorders.

\section{ACKNOWLEDGMENT}

Authors are thankful to Dr. kiranmai, Principal, Bharat Institute of Technology for her constant encouragement and support.

\section{CONFLICT OF INTERESTS}

There is no conflict of interest

\section{REFERENCES}

1. Feig DI. Uric acid. A novel mediator and marker of risk in chronic kidney disease. Curr Opin Nephrol Hypertens 2009;18:526-30.

2. Richette P, Bardin T. Gout. Lancet 2010;375:318-28.

3. Smith EU, Diaz-Torne C, Perez-Ruiz F, March LH. Epidemiology of gout. An update. Best Practice Res Clin Rheumatol 2010;24:811-27.

4. Pande I. An update on gout. Indian J Rheumatol 2006;1:60-5.

5. Saag KG, Mikuls TR. Recent advances in the epidemiology of gout. Curr Rheumatol Rep 2005;7:235-41.

6. Ichida K, Amaya Y, Noda K, Minoshima S, Hosoya T, Sakai O, et al. Cloning of the cDNA encoding human xanthine dehydrogenase (oxidase): structural analysis of the protein and chromosomal location of the gene. Gene 1993;133:279-84.

7. Cazzaniga G, Terao M, Lo Schiavo P, Galbiati F, Segalla F, Seldin $\mathrm{MF}$, et al. Chromosomal mapping, isolation, and characterization of the mouse xanthine dehydrogenase gene. Genomics 1994;23:390-402.

8. Minoshima S, Wang Y, Ichida K, Nishino T, Shimizu N. Mapping of the gene for human xanthine dehydrogenase (oxidase) (XDH) to band p23 of chromosome 2. Cytogen Cell Gen 1995;68 (1, Suppl 2):52-3.

9. George J, Struthers AD. Role of urate, xanthine oxidase and the effects of allopurinol in vascular oxidative stress. Vas Health Risk Manag 2009;5:265-72.

10. Reuter S, Gupta SC, Chaturvedi MM, Aggarwa BB. Oxidative stress, inflammation, and cancer: how are they linked? Free Radical Biol Med 2010;49:1603-16.

11. Sachidanandam C, Fagan SC, Ergul A. Oxidative stress and cardiovascular disease: antioxidants and unresolved issues. Cardiovasc Drug Rev 2005;23:115-32.
12. Uma Rajeswari B, Kiranmai M. Biochemical role of xanthin oxidoreductase and its natural inhibitors. Int J Pharm Pharm Sci 2016;8:57-65.

13. Matsumoto K, Okamoto K, Ashizawa N, Nishino T. FYX-051: a novel and potent hybrid-type inhibitor of xanthine oxidoreductase. J Pharmacol Exp Ther 2011;336:95-103.

14. Hande KR, Noone RM, Stone WJ. Severe allopurinol toxicity, description and guidelines for prevention in patients with renal insufficiency. Am J Med 1984;76:47-56.

15. Abeles AM. Febuxostat hypersensitivity. J Rheumatol 2012;39:659.

16. Changyi Chen, Jian Ming Lu, Qizhi Yao. Hyperuricemia-related diseases and xanthine oxidoreductase (XOR) inhibitors: an overview. Med Sci Mon 2016;22:2501-12.

17. Pandey M, Debnath M, Gupta S, Chikara SK. Phytomedicine: an ancient approach is turning in to future potential source of therapeutics. J Pharmacognosy Phytother 2011;3:27-37.

18. Umezawa H. Enzyme inhibitors of microbial origin. Univ Tokyo Press; 1972. p. 109.

19. Ajay Kumar, Wamik Azmi. Phytomedicine: a novel alternative for treatment of gout. Ann Phytomed 2014;3:80-8.

20. Bhupinder Kapoor, Gagandeep Kaur, Mukta Gupta, Reena Gupta. Indian medicinal plants useful in treatment of gout: a review for current status and future perspective. Asian J Pharm Clin Res 2017;10:407-16

21. Rohit R Patil, Gajanan S Patil. A review: antigout medicinal plants. Eur J Biomed Pharm Sci 2018;5:394-402.

22. Ling $X$, Bochu W. A review of phytotherapy of gout: perspective of new pharmacological treatments. Pharmazie 2014;69:243-56.

23. Ojha R, Singh J, Ojha A, Singh H, Sharma S, Nepali K. An updated patent review: xanthine oxidase inhibitors for the treatment of hyperuricemia and gout (2011-2015). Expert Opin Ther Pat 2017;27:311-45.

24. Schindler P, Hartley BS, Brenner S. Enzyme inhibitors of microbial origin. Phil Trans Royal Soc London B 1980;290:291301.

25. Pandey A, Selvakumar P, Soccol CR, Nigam P. Solid-state fermentation for the production of industrial enzymes. Curr Sci 1999;77:149-62.

26. Panda H. Handbook on drugs from natural sources. Asia Pacific Business Press Inc; 2000. p. 1-34.

27. Suahara N, Nogi K, Yokogava K. Production of xanthine oxidase inhibitor, 2,8-Dihydroxy adenine by Alcaligenes aquamarinus. Agric Bioll Chem 1977;41:1103-9.

28. Cavalieri LF, Bendich A. The ultraviolet absorption spectra of pyrimidines and purines. J Am Chem Soc 1950;72:2587-94.

29. Izumida $\mathrm{H}$, Adachi $\mathrm{K}$, Nishijima $\mathrm{M}$, Endo $\mathrm{M}$, Miki W. Akalone: a novel xanthine oxidase inhibitor produced by the marine bacterium, Agrobacterium aurantiacum sp. nov. J Marine Biotechnol 1995;2:115-8.

30. Izumida $H$, Adachi $K$, Mihara A, Yasuzawaft $T$, Sano $H$. Hydroxyakalone, a novel xanthine oxidase inhibitor produced by a marine bacterium, Agrobacterium aurantiacum. J Antibiotics 1997;50:916-8.

31. Siao Jen Chen, Yen-Lin Chen, Hsun Yin Hsu, Shy Yunn Wann Novel strains of lctobacillus rhamnosus and its metabolites for use in inhibing xanthine oxidase and treating gout. US2016/0051602AD; 2016.

32. Siao Jen Chen, Yen Lin Chen, Hsun Yin Hsu, Shy Yunn Wann. Novel acetobacter and gluconobacter strains and their metabolites for use in inhibiting xanthine oxidase. US2016/0051596A1; 2018.

33. Siao Jen Chen, Yen Lin Chen, Hsun Yin Hsu, Shy Yunn Wann. Acetobacter and Gluconobacter strains and their metabolites for use in inhibiting Xanthine oxidase. US9,86,7857 B2; 2018.

34. Yamamoto Y, Miura Y, Higuchi M, Kinoshita Y, Yoshimura I. Using lichen tissue culture in modern biology. Bryologist 1993;96:384-93.

35. Yamamoto Y, Kinoshita Y, Matsubara H, Kinoshita K, Koyama K, Takahashi $\mathrm{K}$, et al. Screening of biological activities and isolation of biological-active compounds from lichens. Res J Phytochem 1998;2:23-34. 
36. Behera BC, Adawadkar B, Makhij U. Tissue culture of Bulbothrix setschwanensis (lichenized ascomycetes) in vitro. Curr Sci 2000;78:781-3.

37. Behera BC, Urmila Makhija. Inhibition of tyrosinase and xanthine oxidase by lichen species Bulbothrix setschwanensis. Curr Sci 2002;82:61-6.

38. Behera BC, Adawadkar B, Makhij U. Capacity of some graphidaceous lichens to scavenge superoxide and inhibition of tyrosinase and xanthine oxidase activities. Curr Sci 2004;87:83-7.

39. Nisa H, Kamiti AN, Nawchoo IA, Shafi S, Shameen N, Bandh SA. Fungal endophytes as a prolific source of phytochemicals and other bioactive natural products: a review. Microboil Pathol 2015;82:50-9.

40. Tan RX, Zou WX. Endophytes: a rich source of functional metabolites. Nat Prod Rep 2001;18:458-9.

41. Zhang HW, Song YC, Tan RX. Biology and chemistry of endophytes. Nat Prod Rep 2006;23:828-9.

42. Song YC, Li H, Ye YH, Shan CY, Yang YM, Tan RX. Endophytic naphthopyrone metabolites are co-inhibitors of xanthine oxidase, SW1116 cell and some microbial growths. FEMS Microb Lett 2004;241:67-72.

43. Shu RG, Wang FW, Yang YM, Liu YX, Tan RX. Antibacterial and xanthine oxidase inhibitory cerebrosides from Fusarium sp. IFB-121, and endophytic fungus in quercus variabilis. Lipids 2004;39:667-73.

44. Huang WY, Cai YZ, Hyde KD, Corke H, Sun M. Endophytic fungi from Nerium oleander L (Apocynaceae): main constituents and antioxidant activity. World J Microb Biotechnol 2007;23:1253-63.

45. Kapoor N, Saxena S. Xanthine oxidase inhibitory and antioxidant potential of Indian Muscodor species. 3 Biotech 2016;6:248.

46. Neha Kapoor, Sanjai Saxena. Endophytic fungi of Tinospora cordifolia with anti-gout properties. Biotechnology 2018;8:264 70.

47. Kapoor N, Saxena S. Potential xanthine oxidase inhibitory activity of endophytic Lasiodiplodia pseudotheobromae. Appl Biochem Biotechnol 2014;173:1360-74.

48. Wasser SP. Medicinal mushrooms as a source of antitumor and immunomodulating polysaccharides. Appl Biochem Biotechnol 2002:60:258-74.
49. Mahajna J, Dotan N, Zaidman BZ, Petrova RD, Wasser SP. Pharmacological values of medicinal mushrooms for prostate cancer therapy: the case of Ganoderma lucidum. Nutr Cancer 2009;61:16-26.

50. Rastelli G, Costantino L, Albasini A. Theoretical and experimental study of flavones as inhibitors of Xanthine oxidase. Eur J Med Chem 1995;30:141-6.

51. Vanishree B, Dayanand CD, Sheela SR. Evaluation of xanthine oxidase inhibitory activity by flavonoids from pongamia pinnata Linn. Asian J Pharm Clin Res 2017;10:360-2.

52. Chang WS, Lee YJ, Lu FJ, Chaing HC. Inhibitory effects of flavonoids on xanthine oxidase. Anticancer Res 1993;13:2163-70.

53. Lio M, Moriyama A, Matsumoto Y, Takaki N, Fukumoto M. Inhibition of xanthine oxidase by flavonoids. Agric Biol Chem 1985;49:2173-6.

54. Hilaire V, Kemami Wangun. Inotilone and related phenylpropanoid polyketides from Inonotus sp. and their identification as potent COX and XO inhibitors. Org Biomol Chem 2006;4:2545-8.

55. Alam N, Yoon KN, Jeong C. Appraisal of the antioxidant, phenolic compounds, concentration, xanthine oxidase, tyrosine oxidase inhibitory activities of Pleurotus salmoneoshamineus. Afr JAgric Res 2011;6:1555-63.

56. Alam N, Yoon KN, Tae Soo Lee. Evaluation of the antioxidant and antityrosinase activities of three extracts from Pleurotus nebrodensis. Afr J Biotechnol 2011;10:2978-86.

57. Jang IT, Hyun SH, Lee YH. Characterization of an anti-gout xanthine oxidase inhibitor from pleurotus ostreatus. Mycobiology 2014;42:296-300.

58. Kovacs B, Zomborszki ZP, Gyapai O0, Loffler JC, Busa EL, Lazar A et al. Investigation of antimicrobial, antioxidant, and xanthine oxidase-inhibitory activities of Phellinus (Agaricomycetes) mushroom species native to central Europe. Int J Med Mushrooms 2018;20:387-94.

59. Yang HS, Choi YJ, Oh HH, Moon JS. Antioxidant activity of mushroom water extracts fermented by Lactic acid bacteria. J Korean Soc Food Sci Nutr 2014;43:80-5.

60. Attila Ványolós, Orsolya Orbán-Gyapai and Judit Hohmann. Xanthine Oxidase Inhibitory Activity of Hungarian WildGrowing Mushrooms. Phytother Res 2014. 